\title{
Effect of Workplace Stress on Marital Adjustment and Marital Satisfaction among females across Mumbai
}

\author{
Noelangela Nadar \\ Masters in Counselling Psychology, Maniben Nanavati Women's College, Mumbai. \\ Corresponding author: Noelangela Nadar \\ Email-nadarnoelangela69@gmail.com
}

\begin{abstract}
Background and Objectives: The research aimed at studying Marital Adjustment and Marital Satisfaction in participants experiencing high workplace stress and low workplace stress residing in Mumbai. The sample size consisted of 120 working females i.e. 60 participants experiencing high workplace stress and 60 participants experiencing low workplace stress.

Methods: The Convenience and Snowball non-probability sampling method was used to collect data in person and online through google forms. The tools employed were Marital Adjustment Test (MAT) given by Locke, H.J., Wallace, K.M. (1959), Relationship Assessment Scale (RAS) given by Hendrick, S.S (1988) and Workplace Stress Scale (WSS) given by Harris Interactive, Marlin Company, North Haven and The American Institute of Stress (2006).

Results: Descriptive statistics was used to calculate statistical properties and age of the participants. To find the difference between two groups WSS (High and Low), independent t-test was used to find the significance level. The $t$ value obtained for MAT was -.760 and RAS was -1.763 with degree of freedom 118 . The results obtained were found to be insignificant.

Conclusion: The findings indicate that the workplace stress category of females had no effect on marital adjustment as well as on marital satisfaction. However, despite supporting past studies, it was found that there was no significant relationship between the levels of workplace stress and marital adjustment and marital satisfaction.
\end{abstract}

Keywords: Marital adjustment, marital satisfaction, workplace stress.

(Paper received $-9^{\text {th }}$ August 2018, Peer review completed $-20^{\text {th }}$ September 2018) (Accepted $-24^{\text {th }}$ September 2018)

\section{INTRODUCTION}

Marriage is considered as the most important and fundamental human relationship. In India, marriages are done in different ways due to different cultures, castes and traditions. In the past, only males used to work and females used to take care of family and children. In today's $21^{\text {st }}$ century every girl gets educated and pursues her career after marriage. With females becoming more autonomous they face many other issues. Marriage is also said to provide an individual the primary structure to establish a family relationship and raise the next generation [1].

A good marriage is referred to a partnership that is based on love and mutual respect. Marriage is also said to involve a very close and intimate relationship between husband and wife. Marriage can be defined as, "A comprehensive union; a union of will (by consent) and body (by sexual union) inherently ordered to procreation and thus the broad sharing of family life; and calling for permanent and exclusive commitment, whatever the spouses' preferences" [2]. Every intimate relation is said to be based on three key factors: (a) Love to each other; (b) Care to each other; (c) Sharing experiences with each other [3]. Various studies have suggested that $25 \%$ to $40 \%$ of workers reported to face too much stress on the job; and, about $56 \%$ of them have a spouse who is probably suffering the same. With today's couple playing 
dual-roles, stress is coming up. And this family and work stress management becomes difficult and it seems to affect their marriage life. Elliot Rosen [4], said, "Stress is called to be enormously contagious," and it can damage marriages unless steps are taken to manage it. Elliot had also further described about workplace stress and its effect on an individual social life. He defined Workplace stress as, "the harmful physical as well as emotional responses that can occur when there is a conflict between job demands on the employee and the amount of control an employee has over meeting these demands". In most of the countries, work-life balance is shockingly poor and is very much damaging person's relationships and overall wellbeing - as well as productivity. Hence employers need to take more responsibility for the pressure that stress and lack of work-life balance put on relationships at home [5].

Work-related stress or occupational stress is determined by work organization, work design and labor relations and is occurred when the demands of the job do not match or exceed the capabilities, resources, or needs of the worker, or when the knowledge or abilities of an individual worker or group to cope are not matched with the expectations of the organizational culture of an enterprise [6].

When pressure is built in our working lives, it is said to lead to spill over to create pressure in our relationships. When a girl enters a new family, she comes into contact with other members of the family i.e. her in-laws and also plays many important roles like bride, wife, daughter-in law and others. The quality and quantity of her interaction with them bring an enormous influence upon her adjustment in her marital life [7].

According to Schneider [8], Marital Adjustment is said to be the ability to meet day to day demands, changes and responsibilities of marriage with whatever degree of emotional calmness and efficiency is required at the time. It also involves getting along with and enjoying the companionship of the marital partner, participating in the interest and activities of the family group accepting additional responsibilities as they arise and changing one's style of life to correspond with changing in the family life.

Marital adjustment is referred to the state of accommodation which is achieved in different areas where conflict may exist in marriage [9]. Locke and Williamson have defined Marital adjustment as the presence of the characteristics in a person used to avoid or resolve conflicts in marriage and with each other at home, and fulfilling the needs of husband or wife [10].

Many social scholars have tried to find out the characteristics that might assure marital adjustment and marital happiness which is called the "blessed state" [11]. On the basis of factor analysis study of marital adjustment by Locke and Williamson, marital adjustment is redefined as, "An adoption between husband and wife to the point where there is companionship, agreement on basic values, affectional intimacy, accommodation, euphoria, and certain other unidentified factors" [10].

Relationship satisfaction also plays an important role which is said to be linked in different ways to men's and women's abilities to read each other's emotions, and also seem to relate more to positive emotions for men and negative emotions for women. Men's satisfaction is in his ability to identify when his wife is happy, but not when she is angry or upset. In contrast, women's satisfaction is in her ability to read when her husband is upset, hurt, or angry, but not when he's happy [12].

Hence, marital or relationship satisfaction is referred to the attitude an individual has toward his or her marital relationship [13]. Marital satisfaction is also referred to an individual's subjective evaluation of the marital relationship [14]. Marital Satisfaction is defined as, "A special case of relationship satisfaction, and is the degree to which partners in marriages assess their approval of different aspects of their marital relations" [15].

Many authors have further described marital satisfaction as "a complex and multidimensional phenomenon [16], which has been extensively explored by the most diverse scientific fields [17-18]. Factors of cultural, religious, legal and educational origins, among others, are said to help to shape an individual's ideal of what is necessary for constituting an affective relationship, especially a marital one [19-20].

Marital satisfaction was also defined by Gelles [21] as an individual's subjective evaluation of the overall nature of marriage" and that reflects the degree to which an individual's expectations towards marriage are exhibited in his/her own marriage.

In today's era women are becoming increasingly independent and are no longer required to look to the partner for financial support. It has also been seen that there are increasingly instances that married couples are separating due to the willingness of either or both partners to compromise. They find it easier to get 
separated than put in the effort of working towards solving problems that are bound to arise in a relationship where two people live in such close relationship. And the problems can be caused due to many reasons but as both husband and wife go for work they find it difficult to handle both work and family pressure. But in our Indian culture it's been seen that women play and have got many roles and responsibilities to do in her family. She is considered to be the most important person to take care of her husband, children and her inlaws. But at most times her work pressure affects her time to be given for the family and their needs especially their husband. This also impairs her relationship with her husband and family and makes her difficult to adjust many family situations. Hence, the researcher felt that the stress faced in workplace has major effect in the couple's marriage life. Therefore, the researcher proposes this study to understand about the effect that workplace stress has on females' marriage life.

\section{THEORETICAL PERSPECTIVE}

\section{Workplace Stress}

World Health Organization (WHO) had described that workplace stress stems from unexpected responsibilities and pressures that do not align with a person's knowledge, skills, or expectations, inhibiting one's ability to cope. And this stress can increase when workers do not feel supported by supervisors or colleagues, or feel as if they have little control over work processes. Researchers [22] categorized occupational or workplace stress' theories as interactional or transactional.

\section{Interactional theories}

Interactional theories of stress focused on the structural features of the persons' interaction with their work environment [23]. At early times, researchers used fundamental input-output or stimulus-response approaches, in which whereby the major life events or features of work design had predicted a negative outcome, be it, psychological, physiological or behavioural [24]. Theoretically, the environmental-stimulusindividual response cause is known as the stressors and strain approach. The relationship between these stressors and strain is considered to be causal. The central point of this theory of stress is the structural appearance of the person's communication with their work environment.

\section{Transactional theories}

Transactional theories of stress focused on the persons' touching response which is related to their surroundings. The traditional causal model of stress had prolonged from an unidirectional conceptualization to a transactional explanation, whereby stress is explained as an whereby stress is "entrenched in an ongoing ten procedures that would involve individuals handling with their environments, making appraisals of those encounters, and efforts to cope with the issues that arise" [25]. This theory of stress centred on the person's moving reactions and cognitive development related to their environment.

\section{Person-Environment Fit model, developed by French}

According to this model the stress and strain in workplace is caused by the interaction of the worker with his or her environment. According to French and his colleagues [26], job stress occur if an individual lack the capabilities, skills or resources which are needed to satisfy the demands of her or his work and organizational climate.

\section{Beehr and Newman's facet model}

Beehr and Newman in their model have explained that stress faced in workplace can be broken down into a number of facets. They had described one of the facets like, personal facet which refers to the even characteristics that employees bring with them to the workplace. Further they also described another facet named as time facet which revealed that the process of individual's sharpness of stressor is embedding with a time context [27]. 


\section{Dynamic Equilibrium theory}

This theory was proposed by Hart and Wearing [28]. This theory deals with the concerns of the role of personality of an individual that play in the stress processes. According to Hart and Wearing, stress is not formulated as a demand, a response or process but as a state of disequilibrium that exist when it had affected the individuals' normal level of psychological well-being.

\section{Marital Satisfaction}

\section{Dynamic goal theory of marital satisfaction- Li \& Fung's three marital goals}

Tianyuan Li and Helene H. Fung have suggested that there are three types of marital goals: personal growth goals, instrumental goals, and companionship goals. The relative importance of these three different marital goals is under dynamic changes across adulthood. In brief, young couples emphasize personal growth goals, middle-aged couples prioritize instrumental goals, and old couples focus on companionship goals. Prioritized marital goals can further affect marital interaction patterns to facilitate the achievement of marital satisfaction.

These marital goals also provide an ungenerous way to integrate previous research about marital satisfaction from the developmental perspective, and contributes to both the literature on marriage and that on life span development. Various influencing factors of marital satisfaction are said to be organized around the central concept of marital goal. Moreover, the classification of marital goals, the changing priority of marital goals across adulthood, and the relationship between marital goals and other influencing factors of marital satisfaction are said to also provide promising directions for empirical investigations in the future [29].

\section{Social Exchange theory}

This theory provides framework to assess marital and family relational processes in relationships' satisfaction. However, Social exchange theory, is said to define marital relationship as an exchange system, not just as a matter of rewards and costs, but also as a matter of reciprocal behaviour, with different degrees of reciprocity, trust, unequal power, value, utility, outcome, norms, and social conditions for interpersonal behaviour which are complementary in some situations, competitive in others and, in yet others, altruistic [30]. But the ultimate value of this work may lie in its ability to provide a framework for future research in the study of marital and family relationships, and to sharpen the theoretical focus of that research.

According to a metanalysis of more than 100 longitudinal studies of marriage, theoretical accounts of why specific spouses and couples achieve particular outcomes had put attention to one of three primary domains of influence, they include: personality traits and experiences prior to marriage (e.g., negative affectivity, parental divorce), the stressful events and circumstances that spouses and couples encounter once they are married (e.g., stress relating to work and health, transition to parenthood), and the emotions and communication skills spouses display while adapting to each other and the stress they confront (e.g., expressions of affection, displays of anger and aggression) [31].

\section{Psychodynamic Model- by Sigmund Freud}

Freud (1909) is the founder of psychodynamic perspective wherein he described concepts like concept of conscious, unconscious and subconscious state of mind [32]. Psychodynamic perspective states that people consciously and unconsciously want spouses who satisfy their needs. For example, one partner may be dominant and aggressive while the other is submissive and masochistic or one partner may be emotionally detached while other may be emotionally attached [33]. In other words people select spouse who is the best substitute for their needs. "Couples are usually attracted by shared developmental failures" [34]. A second major feature of the psychodynamic formulation of marriage concerns with the role of each spouse's individual psychosexual development in marital functioning. Comfortable differentiation from the family of origin and non-neurotic resolution of the various psychosexual conflicts are thought to result in levels of individual functioning that form the foundation of satisfactory marital relations [35]. A final and important feature of the theory, individual levels of neuroticism are thought to influence directly the adjustment of the couple. 


\section{Social Learning Model}

This model of marriage was developed after the social exchange theory. By explaining this model they used the term 'social exchange'. And defined social exchange as the exchange of activity, tangible or intangible, and more or less rewarding or costly, between the husband and wife [36].

\section{Behavioural Perspective}

Behaviour features were explained by many scholars on the basis of the day to day behaviour of spouses. This model tried to distinguish between distressed and non-distressed married couples. And it was found that distressed couples were involved in fewer recreational activities than the non-distressed couples [37]. Distressed couples was also found to spend less time together [38], and that the partners' rated the time they spent together more negatively on the basis of displeasing behaviour during their time together. In studies of verbal behaviour it was found that the distressed couples made more negative statement (disagreements, criticisms) and fewer positive ones [39-40]. Distressed couples were also found conformative, complaining and defensive with spouses than they were with other people [41].

\section{Cognitive Perspective}

The cognitive correlates of marital satisfaction are given in the form of certain attributions and appraisals about the spouses' marriage. Their studies showed that distressed couples were less likely to interpret objectively positive behaviour from their spouses as positive, by underestimating the positivity [42].

\section{METHODOLOGY}

\section{Research Questions}

1. The following are the research questions:

2. What effect will workplace stress have on marital adjustment and marital satisfaction among females age between 25 to 45 years?

3. Will high workplace stress lead to high marital adjustment among females?

4. Will high workplace stress lead to high marital satisfaction among females?

\section{Aim}

To study workplace stress effecting marital adjustment and marital satisfaction among females across Mumbai.

\section{Objective}

1. To compare scores of Workplace stress with scores of Marital Adjustment.

2. To compare scores of Workplace stress with scores of Marital Satisfaction.

\section{Hypotheses}

Following are the hypothesis of the study:

1. High workplace stress category of females would have lower marital adjustment as compared to low workplace stress category of females.

2. High workplace stress category of females would have lower marital satisfaction as compared to low workplace stress category of females.

\section{Variables}

1. Independent Variable - Workplace Stress

- High Workplace Stress

- Low Workplace Stress

2. Dependent Variables

- Marital Adjustment

- Marital Satisfaction 


\section{Operational definitions}

i. Workplace Stress as measured by scores on the Workplace Stress Scale (WSS) given by Harris [43]. Categories of this was done using median split where midpoint score was 49.5

- High Workplace stress was those above 49.5

- Low Workplace stress was those below 49.5

ii. Marital Adjustment as measured by scores on the Marital Adjustment Test (MAT) [44].

iii. Marital Satisfaction as measured by scores on the Relationship Assessment Scale (RAS) [45].

\section{Participants and Control Variables}

\section{Sample}

The sample consisted of 120 working females who belonged to different occupations. Their age range between 25 to 40 years (mean $=31.13 \mathrm{SD}=5.071$ ). The criteria for the research entailed that all the females were married and were having at least one child but not more than 3 . The data was collected from different organizations like office setting, schools, colleges and even at their homes. Mostly the data from them was collected through email.

\section{Inclusion Criteria:}

1. Married females

2. Females having at least one child

3. Familiar with English language

4. Between the age range of $25-45$ years

5. Residing in Mumbai

\section{Exclusion Criteria}

1. Unmarried females

2. Females having more than 3 children

3. Unfamiliar with English language

4. Not meeting the age criteria

5. Not residing in Mumbai

\section{Other Controls}

1. The scales would be administered in a peaceful atmosphere with minimal noise and distractions.

2. It will be administered in person or through email.

\section{Research Design}

The design of the research is between group design and survey method using questionnaires was used to collect data. And median split was used to categorize the Independent variable i.e. Workplace stress into High and Low workplace stress. And further the scores were interpreted, where scores below the midpoint belonged to low workplace stress and scores above the midpoint belonged to high workplace stress.

\section{Sampling Method}

Non-probability sampling method was used to collect data. The techniques included convenience and snowball sampling. Convenience sampling was a technique where the subjects are selected because of the convenient accessibility and close at hand of the researcher. Snowball sampling was a technique also called as chain sampling where the subjects further get more subjects for study and those subjects get some more and chain goes on. 


\section{Research Instruments}

a. Workplace Stress Scale (WSS) - The WSS consist of 10 items scale with 10-point Likert scale, range from 1 (strongly disagree) to 10 (strongly agree). The total score is obtained by summing up the responses. Content validity was obtained by seeking experts from American workers. The reliability of WSS using Cronbach alpha came out to be 0.690 [43].

b. Marital Adjustment Test (MAT) - The MAT consists of 15 items that measures marital adjustment. The scoring varies from item to item and total score is calculated done by summing up all items. Content validity was established from heterosexual couples only and was found to be 0.83 . Reliability found was .90 . There are also three factors identified which includes Sexual Congeniality, Compatibility and Closeness [44].

c. Relationship Assessment Scale (RAS) - RAS is a 7-items scale designed to measure relationship satisfaction. Respondents answer each item using a 5-point Likert scale ranging from 1 (low satisfaction) to 5 (high satisfaction). Item 4 and 7 are reverse-scored. The reliability was found to be .86 and construct validity was found to be .80 [45].

\section{Procedure}

The study was conducted in Mumbai focusing on married females between the ages of 25-45 years. 100 participants were selected using non-probability techniques and they belonged to different occupations. They were first explained about the study and once they agreed to participate they were given a form for demographic details, a consent form and a copy of the Workplace Stress Scale, Marital Adjustment Test, and Relationship Assessment Scale. The females who were willing to participate in the study were provided with standardized instructions before the administration. They were explained the purpose and relevance of the study. After each female finished with the survey and the materials were collected, the students were thanked for participating in the study. After each survey was collected from the centres, data were scored, coded and entered into an excel spreadsheet. Futher, the data were calculated using SPSS (Statistical Package for Social Science)

\section{STATISTICAL ANALYSIS}

The analysis was done using descriptive statistics to find Mean, median and SD. Then the means of the data i.e. the levels of Workplace stress with Marital Adjustment and Marital Satisfaction were compared using $t$ test. The results showed whether there was any significant difference between two levels of workplace stress.

\section{RESULTS}

The study was primarily carried out to examine whether there's an effect of workplace stress on Marital Adjustment and Marital Satisfaction. 120 female participants between the age group of 25-40 years belonging to different occupations were part of the study. The researcher provided information to the participants regarding the objective of the research, scales and the principle of confidentiality. The Workplace stress scale, Marital Adjustment Test, Relationship Assessment Scale were administered on each of the participants. The result collected was quantitatively analysed. Descriptive Statistics of the variables were calculated (Table 1). There is one independent variable i.e. Workplace stress having two levels i.e. High workplace stress and Low workplace stress. Assuming the normality distribution of the data the hypotheses was tested using the inferential statistics i.e. independent t-test was applied.

Table 1: Descriptive Statistics of the variables

\begin{tabular}{|l|l|l|l|}
\hline Variable & N & Mean & SD \\
\hline WSS & 120 & 48.23 & 12.61 \\
\hline MAT & 120 & 108.18 & 22.07 \\
\hline RAS & 120 & 30.11 & 4.86 \\
\hline
\end{tabular}


The descriptive statistics of the entire data revealed that the mean value for the participants' workplace stress scores was 48.23 with the SD of 12.61. The result for the Marital Adjustment with the mean score obtained was 108.18 and SD 22. 07. The mean for Marital Satisfaction on RAS was 30.11 and SD 4.86. (Table 1)

Table 2: Comparison of Mean \& SD of MAT \& RAS on the basis WSS

\begin{tabular}{|l|l|l|l|l|}
\hline VARIABLE & WSS & N & MEAN & SD \\
\hline MAT & High WSS & 60 & 109.72 & 23.2 \\
& Low WSS & 60 & 106.65 & 20.96 \\
\hline RAS & High WSS & 60 & 4.934 & 0.637 \\
& Low WSS & 60 & 4.693 & 0,606 \\
\hline
\end{tabular}

The descriptive statistics of the data shown in Table 2 on the basis of WSS with the mean value for the participant's High WSS on Marital Adjustment was 109.72 with a SD of 23.2 and the mean score participant's Low WSS on Marital Adjustment was 106.65 with a standard deviation of 20.96.

Referring to table 2, the descriptive statistics data of RAS on basis of WSS revealed that the mean value for the participant's scores with High WSS was 4.934 with a standard deviation of 0.637 and the mean score with Low WSS was 4.693 with a standard deviation of 0.606 .

Table 3: Calculated t-test for WSS of participant's scoring on MAT \& RAS

\begin{tabular}{lcccc}
\hline Variable & & t-value & df & significance \\
\hline MAT & -.760 & 118 & $0.449(\mathrm{NS})$ & \\
\hline RAS & & -1.763 & 118 & $0.080(\mathrm{NS})$ \\
\hline
\end{tabular}

The first hypothesis tested whether High workplace stress category of females would have lower marital adjustment as compared to low workplace stress category of females; with the Reference to table 3, the obtained $\mathrm{t}$ value for participants on MAT was -.760. The degree of freedom is 118 and the level of significance was 0.449 . Since the obtained value is more than 0.05 level of significance, the data is not statistically significant. In the lieu of the above result, the first hypothesis was not verified. Hence the hypothesis 1 is rejected and the null hypothesis is accepted. But in reference to table 1 mean differences between two groups in noticed i.e. the participants having High WSS face Low Marital Adjustment than participants having Low WSS.

The second hypothesis tested whether participants with High workplace stress category would have low marital satisfaction as compared to low workplace stress category; with the Reference to table 2, the obtained $\mathrm{t}$-value for participants on Perceived Stress Scale is -1.763 . The degree of freedom is 118 and the level of significance is 0.080 . Since the obtained value is more than 0.05 level of significance, the data is not statistically significant. In the lieu of the above result, the second hypothesis was not verified. Hence, the hypothesis 2 is rejected and the null hypothesis is accepted. But in the reference to table 1, mean differences between two groups is noticed i.e. the participants having High WSS face Low Marital satisfaction than participants having Low WSS.

\section{DISCUSSION}

The purpose of this research was to study workplace stress effecting marital adjustment and marital satisfaction among females across Mumbai. This study is important as it provided insight into how the levels of workplace stress or the tension or pressure experienced due to work setting or job affected marital adjustment, which involves adjusting or state of accomodation in different areas of marriage life for females across Mumbai. This study also important as it provided an insight into how the levels of workplace stress affected martial satisfaction, which involves satisfaction with partner's relationship. The females were 
working with different organizations and belonged to different occupations. In this situation, how the females are well adjusted and satisfied with their marriage life is determined by the levels of workplace stress. Descriptive statistics and independent samples $t$ test were conducted on working females to compare martial adjustment and marital satisfaction on categories of high and low levels of workplace stress by using median split.

The first research hypothesis was High workplace stress category of females would have lower marital adjustment as compared to low workplace stress category of females. The statistical result obtained was found to be not in line with the hypothesis and also not in line with previous studies.

The second research hypothesis was High workplace stress category of females would have lower marital satisfaction as compared to low workplace stress category of females. The statistical result found wasn't in line with the hypothesis and also in line with past studies.

It was also assumed that there could be other confounding variables that could have been influenced the results. As reported in the study between housewives $(\mathrm{N}=200)$ and working women $(\mathrm{N}=200)$. Results revealed that the working women have better general health, life satisfaction and high self esteem which could allow them to make better marital adjustment. [46].

In a study done in the hospital of Zahedan on 103 nurses it was found that their better physical health and better coping of emotional problems showed positive relation with their marital satisfaction. The findings also suggested that even though the nurses faced stress in their work due to better physical health and emotional strength, the stress didn't have negative impact on their marriage life [47].

A dyadic analysis was done between work-family enrichment (WFE), work-family conflict (WFC) and marital satisfaction on dual earner couples. A sample of 215 dual-earner couples with children were studied. Results showed that positive relationship between work-family enrichment and marital satisfaction. It was also found that couples who have better WFE could crossover the effects of WFC and have better marital satisfaction. Study also showed that Husbands who experienced more WF enrichment were found to show more marital positivity (according to their wives), which related to increased marital satisfaction in their wives [48].

In a study on 361 Chinese couples investigated work-family enrichment (WFE) crosses over to have effect on marital satisfaction of the partners. Results showed that husbands' WFE related to wives' marital satisfaction through wives' perceptions showed increased social support, whereas wives' WFE related to husbands' marital satisfaction through husbands' perceptions showed decreased social undermining. Findings also suggested that perceptions of the partner's behaviors as a relevant mechanism to explain the transmission between work and marriage within the same individual [49].

In this study on couple communication as a mediator between work-family conflict and marital satisfaction. Researcher had employed 117 individuals using structural equation modelling and found that work-family conflict was significantly negatively related to marital satisfaction. Results also suggested that teaching communication skills may be a valuable point of intervention for couples who experience high levels of work-family environment [50].

The confounding factors that could include freedom of communication, support, motivation and care they get from their family members especially spouse. And other factors which contributed to the obtained results contrary to the hypothesis could be that the females could cope up with work-family conflict and that helped them to experience less stress and anxiety in their marriage life. These factors helped them have strong and healthy marital relationships. It could have also happened that the females deceived the responses under the pretext of social desirability which lead to contrary results.

\section{Limitations of the study}

This study showed about what factors in the levels of workplace stress influenced the married life of females. The limitations of the study include- The type of marriage i.e. love or arrange and type of family i.e. nuclear or joint weren't considered, hence the marital satisfaction and marital adjustment may have varied. Since the study was done on females having only child and also females with more than one child, marital adjustment and marital satisfaction differed. Since socio-economic status wasn't considered, there could be factors along with workplace stress like financial problems influencing marital adjustment and satisfaction. Since two of the scales i.e. The MAT and the RAS have been developed in 1950s and 1980s, their relevance 
in today's day and age could be questioned. Future research in these factors could examine factors related to occupation, work-organizational support, level of education of females, coping styles of married females in their marriage life, age of the children, anxiety, emotional intelligence, socio-economic status, cultural factors, work status of both partners, societal and relationship expectations and so forth.

\section{CONCLUSION}

The purpose of the study was to examine whether there is an effect of workplace stress on marital adjustment and marital satisfaction among females across Mumbai. The inferential statistics of independent sample ttests was used to analyse the data. The findings indicate that the workplace stress category of females had no effect on marital adjustment as well as on marital satisfaction. However, despite supporting past studies, it was found that there was no significant relationship between the levels of workplace stress and marital adjustment and marital satisfaction.

\section{REFERENCES}

1. Holman TB, Larson JH, Harmer SL. The development and predictive validity of a new premarital assessment instrument: The preparation for marriage questionnaire. Family Relat 1994;2:46-52.

2. Cummings EM, Merrilees CE, George MW. Fathers, marriages, and families. The role of the father in child development 2010;10:154-76.

3. Sarks K, Krupat S. The Psychological Factors in Marriage. Psychological Dissertation 1998;210.

4. Sheridan M, Peterson BD, Rosen KH. The experiences of parents of adolescents in family therapy: A qualitative investigation. J Marital Fam Ther 2010;36(2):144-57.

5. Cooper CE, Osborne CA, Beck AN, McLanahan SS. Partnership instability, school readiness, and gender disparities. Sociol Educ 2011;84(3):246-59.

6. Selye H. The stress concept and some of its implications. New York: John Wiley \& Sons; 1979.

7. Larson JH, Blick RW, Jackson JB, Holman TB. Partner traits that predict relationship satisfaction for neurotic individuals in premarital relationships. J Sex Marital Ther 2010;36(5):430-44.

8. Homans GC, Schneider DM. Marriage, authority, and fiscal causes: a study of unilateral cross-cousin marriage. Free Press; 1955.

9. Adams C, Laurikietis R. The Gender Trap: Sex and marriage. Virago Press; 1980.

10. Locke HJ, Williamson RC. Marital adjustment: A factor analysis study. Amer Sociol Rev 1958;23(5):562-9.

11. Vaillant CO, Vaillant GE. Is the U-curve of marital satisfaction an illusion? A 40-year study of marriage. J Marriage Fam 1993;2:230-9.

12. Manning WD, Cohen JA. Premarital cohabitation and marital dissolution: An examination of recent marriages. J Marriage Fam 2012;74(2):377-87.

13. Fincham FD, Beach SR. Marriage in the new millennium: A decade in review. J Marriage Fam 2010;72(3):630-49.

14. Taylor ML. North Carolina's Recognition of Tort Liability for the Intentional Infliction of Emotional Distress During Marriage. Wake Forest L Rev 1997;32:1261-8.

15. Snyder DK. Multidimensional assessment of marital satisfaction. J Marriage Fam 1979;2:813-23.

16. Falcke D, Wagner A, Mosmann CP. The relationship between family-of-origin and marital adjustment for couples in Brazil. J Fam Psychother 2008;19(2):170-86.

17. Scorsolini-Comin F, dos Santos MA. Correlations between subjective well-being, dyadic adjustment and marital satisfaction in Brazilian married people. Spanish J Psychol 2012;15(1):166-76.

18. Feeney JA. Adult attachment, emotional control, and marital satisfaction. Personal Relat 1999;6(2):169-85.

19. Lalonde RN, Hynie M, Pannu M, Tatla S. The Role of Culture in Interpersonal Relationships: Do Second

20. Generation South Asian Canadians Want a Traditional Partner? J Cross Cult Psychol 2004;35:503-24.

21. Lucas T, Parkhill MR, Wendorf CA, Imamoglu EO, Weisfeld CC, Weisfeld GE, Shen JC. Cultural and Evolutionary Components of Marital Satisfaction: A Multidimensional Assessment of Measurement Invariance. J Cross Cult Psychol 2008;39:109-23.

22. Wendorf CA, Lucas T, Imamoglu EO, Weisfeld CC, Weisfeld GE. Sex Differences and Similarities in Married Couples: Patterns across and within Cultures. J Cross Cult Psychol 2011;42:340-54.

23. Cavanaugh MM, Gelles RJ. The utility of male domestic violence offender typologies: New directions for research, policy, and practice. J Interpersonal Viol 2005;20(2):155-66.

24. Paley B, Cox MJ, Kanoy KW, Harter KS, Burchinal M, Margand NA. Adult attachment and marital interaction as predictors of whole family interactions during the transition to parenthood. J Fam Psychol 2005;19(3):420-8.

25. Bakker AB, Demerouti E, Dollard MF. How job demands affect partners' experience of exhaustion: Integrating work-family conflict and crossover theory. J Appl Psychol 2008;93(4):901-9. 
26. Jones DJ, Beach SR, Forehand R. Stress generation in intact community families: Depressive symptoms, perceived family relationship stress, and implications for adolescent adjustment. J Soc Personal Relat 2001;18(4):443-62.

27. Bach GR, Wyden P, Rechsteiner G, Aquino M. The intimate enemy: How to fight fair in love and marriage. Avon Books; 1970.

28. Newman JE, Beehr TA. Personal and organizational strategies for handling job stress: A review of research and opinion. Personnel Psychol 1979;32(1):1-43.

29. Nelson TT, Hart A, Morris S. Safe Haven Marriage. Thomas Nelson Inc; 2006.

30. Li T, Fung HH. The dynamic goal theory of marital satisfaction. Rev Gen Psychol 2011;15(3):246-54.

31. Chadwick-Jones JK. Social exchange theory: Its structure and influence in social psychology. New York: Academic Press; 1979.

32. Karney BR, Bradbury TN. The longitudinal course of marital quality and stability: A review of theory, methods, and research. Psychol Bull 1995;118(1):3-34.

33. Freud S. The future prospects of psycho-analytic therapy. In The Standard Edition of the Complete Psychological Works of Sigmund Freud, Volume XI: Five Lectures on Psycho-Analysis, Leonardo da Vinci and Other Works; 1909.

34. Ackerman NW. Interpersonal disturbances in the family. Psychiatry 1954;17(4):359-68.

35. Skinner BF. Beyond freedom and dignity. New York: Bantam Books; 1972.

36. Framo JL. Family of origin as a therapeutic resource for adults in marital and family therapy: You can and should go home again. Fam Process 1976;15(2):193-210.

37. Kelly GA, Thibaut JW. The Psychology of Family. 1955;1:1-101.

38. Birchler GR, Webb LJ. Discriminating interaction behaviors in happy and unhappy marriages. J Consult Clin Psychol 1977;45(3):494-510.

39. Polansky NA, Chalmers MA, Buttenwieser E, Williams DP. Isolation of the neglectful family. Am J Orthopsychiatry 1979;49(1):149-56.

40. Gottman JM. The marriage clinic: A scientifically-based marital therapy. WW Norton \& Company; 1999.

41. Baucom DH, Sayers SL, Duhe A. Attributional style and attributional patterns among married couples. J Personal Soc Psychol 1989;56(4):596-605.

42. Wallerstein JS, Blakeslee S. The good marriage: How and why love lasts. New York: Houghton Mifflin; 1995.

43. Arias I, Beach SR. Validity of self-reports of marital violence. J Family Viol 1987;2(2):139-49.

44. Harris KM, Lee H. The development of marriage expectations, attitudes, and desires from adolescence into young adulthood. Inannual meeting of the Population Association of America, Los Angeles 2006.

45. Locke HJ, Wallace KM. Short marital-adjustment and prediction tests: Their reliability and validity. Marriage and Family Living 1959;21(3):251-5.

46. Hendrick SS. A generic measure of relationship satisfaction. J Marriage Fam 1988;2:93-8.

47. Nathawat SS, Mathur A. Marital adjustment and subjective well-being in Indian-educated housewives and working women. J Psychology 1993;127(3):353-8.

48. Gharibi M, Sanagouymoharer G, Yaghoubinia F. The relationship between quality of life with marital satisfaction in nurses in social security hospital in Zahedan. Global J Health Sci 2016;8(2):178-85.

49. van Steenbergen EF, Kluwer ES, Karney BR. Work-family enrichment, work-family conflict, and marital satisfaction: A dyadic analysis. J Occup Health Psychol 2014;19(2):182-94.

50. Liu H, Ngo HY, Cheung FM. Work-family enrichment and marital satisfaction among Chinese couples: A crossover-spillover perspective. Int J Stress Manag 2016;23(2):209-31.

51. Carroll SJ, Hill EJ, Yorgason JB, Larson JH, Sandberg JG. Couple communication as a mediator between work-family conflict and marital satisfaction. Contemp Fam Ther 2013;35(3):530-45.

$$
\begin{aligned}
& \text { Acknowledgements - Nil } \\
& \text { Conflict of Interest - Nil } \\
& \text { Funding - Nil }
\end{aligned}
$$

